\title{
Performance evaluation of compressed laterite blocks stabilised with cement and gum Arabic
}

\author{
Alladjo Rimbarngaye ${ }^{1 *}$, John N. Mwero ${ }^{2}$ and Erick K. Ronoh ${ }^{3}$ \\ Civil Engineering Master Student, Department of Civil and Construction Engineering, Pan African University Institute \\ for Basic Sciences, Technology and Innovation Hosted at Jomo Kenyatta University of Agriculture and Technology, \\ Kenya $^{1}$ \\ Lecturer, Department of Civil and Construction Engineering, University of Nairobi, Kenya ${ }^{2}$ \\ Lecturer, Department of Agricultural and Biosystems Engineering, Jomo Kenyatta University of Agriculture and \\ Technology, Kenya ${ }^{3}$
}

Received: 03-August-2021; Revised: 19-October-2021; Accepted: 24-October-2021

(C)2021 Alladjo Rimbarngaye et al. This is an open access article distributed under the Creative Commons Attribution (CC BY) License, which permits unrestricted use, distribution, and reproduction in any medium, provided the original work is properly cited.

\begin{abstract}
Compressed stabilized earth blocks are the innovation of building materials replacing the earth blocks commonly called adobe. However, the use of cement or lime to stabilize these blocks is a major problem for the environment because of the emission of greenhouse gases and these materials are not accessible to everyone due to their cost. Finding a natural, environmentally friendly alternative, such as renewable materials and especially biopolymers or natural bi nders, to these types of stabilization materials is vital. The objective of this study was therefore to assess the effects of Gum Arabic (GA) as binder on the structural performance of laterite blocks. Compressed laterite blocks were stabilized with $2 \%$ of cement (C) and various percentages of $G A$, from 0 to $10 \%$. The results showed that $G A$ improved the water absorption, dry density and compressive strength of the blocks and the best results were obtained for blocks with $(2 \% \mathrm{C}+8 \% \mathrm{GA})$. For instance, the compressive strength at 28 days was increased by $27.81 \%$ compared to the control blocks with $2 \%$ cement. Based on the findings from this study, GA can be recommended as a binder in making laterite blocks in a sustainable way.
\end{abstract}

\section{Keywords}

Gum Arabic, Compressed stabilised laterite blocks, Water absorption, Dry density, Compressive strength.

\section{Introduction}

Since the first constructions, earth has been used by man as a basic material [1]. More than a third of mankind lives in earthen buildings, even in today's super-modern world of the 21st century. Earthen structures are better adapted to the climate, more environmentally friendly, more accessible and affordable for all, and offer a very primitive cultural link to nature [2]. However, these earthen structures made of earth blocks have a number of issues (durability problems), including rain erosion, spalling, cross-section reduction, cracking at low compressive and tensile strengths, shrinkage, low strength, and dimensional stability [3-6]. Typically, in order to remedy these problems and build sustainable structures, various conventional additives such as lime, fly ash and cement have been added to soils for soil stabilization [7].

\footnotetext{
*Author for correspondence
}

Of the above-mentioned materials, cement is the most widely used. Unfortunately, these techniques contribute to the destruction of the environment through the emission of greenhouse gases and especially through the fact that they are non-renewable materials and are even not accessible to everyone [2], [7-10]. Moreover, there is a cost associated with the transportation of these materials [11]. During the manufacture of cement, 1 tonne of cement generates 1 tonne of $\mathrm{CO}_{2}$ [9]. It has been demonstrated that Compressed Stabilised Earth Blocks (CSEB) generate $22 \mathrm{~kg} \mathrm{CO}_{2} /$ tonne, concrete blocks $143 \mathrm{~kg} \mathrm{CO}_{2} /$ tonne, fired clay bricks $200 \mathrm{~kg} \mathrm{CO} /$ tonne [12]. It was also demonstrated that during the production of the CSEB, $1 \mathrm{~kg}$ of cement used emits $0.894 \mathrm{~kg}$ of $\mathrm{CO}_{2}[13,14]$. In order to reduce the negative environmental impacts of cement and use environmentally friendly materials, the use of natural biopolymers has been proposed as an alternative in soil stabilization [10], [15-18]. In addition, some research has also been carried out on certain gums for soil stabilisation, mainly xanthan 
gum, gellan gum, agar gum, polyacrylamide and guar gum [7, 10], [18-21]. It is known that limited research has been documented in the field of stabilisation of eastern blocks with Gum Arabic (GA). However, the research carried out by [22] showed a particular interest in the use of GA in the stabilisation of earthen blocks. By varying the content of GA from 0 to $10 \%$ by weight of soil, [22] found that the compressive strength of blocks stabilised with GA increased with increasing GA content. As a result of the interesting results obtained by [22], it was recommended to conduct further research in the stabilization of earthen blocks with GA but in combination with other binders such as cement, lime, etc. It has also been recommended to evaluate the effects of water on blocks stabilised with GA.

In addition, it has been proven that blocks stabilised with $2 \%$ cement have not given satisfactory results $[12,23]$. Nevertheless, from an economic point of view, this percentage is advantageous compared to the range of $4-10 \%$ cement recommended for good performance [6, 12]. Therefore, finding a way to improve the performance of blocks stabilised with $2 \%$ cement would be very beneficial from an environmental and economic perspective. Accordingly, this study was carried out by setting $2 \%$ cement for block stabilisation and varying the GA content from 0 to $10 \%$ in order to evaluate the water absorption, the dry density and the compressive strength of the different types of blocks obtained.

\section{Literature review}

Very recent studies have shown the suitability of using GA in concrete. GA has been shown to have low viscosity and high-water solubility [24]. Because of its attractive properties, it is used in various industries including cosmetics, textiles, pharmaceuticals, encapsulation, lithography and even the food industry. GA has also been used as an additive in a binder for ceramic glazes to reduce the risk of damage during factory handling [25]. Studies have also shown that the addition of GA to concrete has improved the properties of concrete due to the presence of minerals such as sepiolite, palygorskite and mordenite. The compressive strengths of concrete containing GA increased with the dosage of GA, and this dosage range of $0.50-0.75 \%$ is adequate for use [26]. On the other hand, it has been shown that GA at a dosage level of $0.8 \%$ by weight of cement is a dual function concrete admixture, namely a setting accelerator (SA) and a normal water reducer (WR) according to BS EN 934-2 (2009)[27]. It reduces water by $11.5 \%$ without altering the consistency of a reference concrete mix
[27]. Furthermore, GA has also shown its suitability in concrete as superplasticizer in self-compacting concrete at a dosage of $8 \%$ by the weight of cement for water-powder ratio of 1.0, 0.9 and 0.8[28]. Used as a water reducing admixture in cement mortar, GA has also shown its suitability as a retarding admixture in mortar at temperatures between $23{ }^{\circ} \mathrm{C}$ and $25^{\circ} \mathrm{C}$ [29]. In addition, GA has also shown its suitability as a binder in partial replacement of cement in the fabrication of micro-concrete tiles [30] and the production of panels made from sawdust and wood shavings [31].

In the field of soil, there is some research that has been conducted on the use of natural ingredients for earth construction. This research has been based on the oral tradition of ancestors transmitted from one generation to another [2]. Among these natural ingredients is GA. A few laboratory tests were carried out to show the importance of using these natural materials in earthen constructions. From these studies, which were limited only to erosion and abrasion tests, it was recommended to do more research on these natural ingredients in order to show the performance of using them in earthen constructions [2]. In addition, it has been reported that GA is widely used in mud plasters on the African continent as a stabilizer and acts as a waterproofing agent [32]. In Africa, GA is a widely available organic material (a biopolymer). This makes the African continent the world's largest exporter of GA [33]. It has been reported that GA is widely used in mud plasters in Africa as a stabilizer and performs as a waterproofing agent [32]. Furthermore, GA also contributes to enhancement of durability properties of concrete and paint $[2,34]$.

The properties of the GA, namely durability, binder, stabiliser and waterproofing agent, could result from the presence of these three mineral elements which are: sepiolite, palygorskite and mordenite [26, 35]. Sepiolite $\left.\left(\mathrm{Si}_{12} \mathrm{Mg}_{8} \mathrm{O}_{30}(\mathrm{OH})_{4}\left(\mathrm{H}_{2} \mathrm{O}\right)\right)_{4}\right)$ is a hydrated magnesium silicate with a microfibrous morphology and a particular texture that provides a high specific surface area [36]. It acts as a binder when adding small quantities of water. Palygorskite is an aluminiummagnesium silicate that has a fibrous morphology. Their physicochemical characteristics are the result of high surface area, porosity and thermal resistance which makes it an attractive adsorbent. Palygorskite is a crystalline hydrated magnesium aluminium silicate that exists in nature as a fibrous mineral with large surface area, excellent chemical stability and strong adsorption properties [37]. The palygorskite has the theoretical formula: $\mathrm{Si}_{8} \mathrm{Mg}_{5} \mathrm{O}_{20}(\mathrm{OH})_{2}\left(\mathrm{OH}_{2}\right)_{4} \cdot 4 \mathrm{H}_{2} \mathrm{O}$. 
Mordenite is a zeolite mineral with the chemical formula, $\left.\left(\mathrm{Ca}, \mathrm{Na}_{2}, \mathrm{~K}_{2}\right) \mathrm{Al}_{2} \mathrm{Si}_{10} \mathrm{O}_{24} \cdot 7 \mathrm{H}_{2} \mathrm{O}\right)$. Mordenite's molecular structure is a framework containing chains of five-membered rings of linked silicate and aluminate tetrahedra. Its high ratio of silicon to aluminium atoms makes it more resistant to attack by acids than most other zeolites.

It has been proven that blocks stabilised with $2 \%$ cement have not shown satisfactory results [12, 23]. However, from an economic point of view, this percentage is advantageous compared to the range of cement percentage recommended to obtain good performance. Although there are possibilities of using GA in concrete as an additive and a superplasticizer, in ceramic glazes as an additive, in the fabrication of micro-concrete tiles and panels and in mud plasters as a binder, there is a lack of information regarding its use in stabilized earth blocks in combination to other binders such cement, lime, etc. Therefore, it has been recommended to conduct further research on the use of GA in the stabilisation of earthen blocks. Finding a way to improve the performance of blocks stabilised with $2 \%$ of cement would be of great benefit from an environmental and economic point of view. It is in this regard that this study was conducted by fixing $2 \%$ of cement for block stabilisation and varying the GA content from 0 to $10 \%$ in order to evaluate the performance of the different types of blocks obtained.

\section{Methods}

\subsection{Materials}

The study was conducted at the Civil Engineering Laboratory of the Jomo Kenyatta University of Agriculture and Technology (JKUAT), Kenya ( $1^{\circ} 5^{\prime} 45^{\prime \prime} \mathrm{S}$ and $37^{\circ} 0^{\prime} 44^{\prime \prime} \mathrm{E}$ for latitude and longitude, respectively). The materials used in this research were GA, laterite soil, river sand, cement and water.

The GA was obtained locally in Kenya. It was supplied from Isiolo, a county in central Kenya. The laterite soil was acquired locally in Juja, within JKUAT. The sand was supplied fromMeru, a town in eastern Kenya. The cement was pozzolanic cement type CEM IV/32.5R which complies with the Kenyan standards in force (KS EAS 18-1:2001). The source of water used for mixing different materials (cement, soil, sand, GA), curing and various tests were the potable water without impurities supplied from the university system (JKUAT). It complied with the Kenyan water regulations (KS EAS 12, 2014).

\subsection{Methods}

3.2.1Preparation of the solution of GA

After measuring the quantities of GA required for each percentage for the different types of blocks with a balance, these quantities of GA in powder form were dissolved with a quantity of water previously determined during the compaction test to obtain the Optimum Moisture Content (OMC) for Maximum Dry Density (MDD) (Figure 1). These dissolved gum solutions were left for 24 hours to ensure complete dis solution of the GA in the water. To avoid confusion between the different percentages of GA, each bucket containing a given percentage of GA was marked with that percentage using a marker as shown in Figure 1. The resulting solution was sticky and this was then mixed with soil for block production.

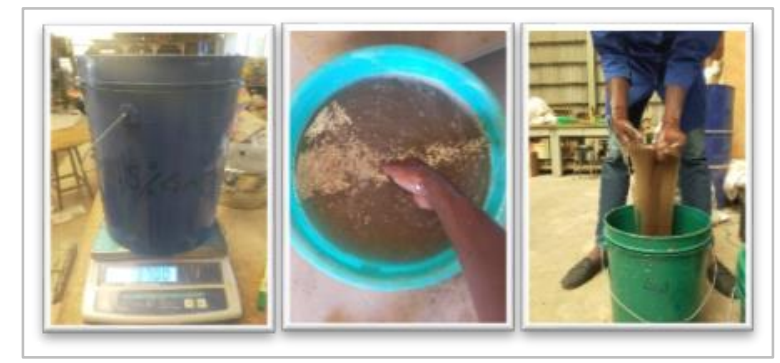

Figure 1 Preparation of the solution of GA

3.2.2Blocks production

As shown in Figure 2, the production of the blocks is summarised in five main steps. The first step was the preparation of the soil, i.e., the soil was sieved on a 5 mm sieve as recommended [38] and then put into bags and transported to the laboratory. The second step consisted of mixing the laterite soil with different proportions of binders, sand and water (Table 1). The amount of water used was the OMC determined during the compaction test on different percentages of GA. Then, the third step was the production of the blocks using the manual press machine. In this step, the mould of the press machine was lubricated by drain oil. Then, the homogeneous mixture of soil with the obtained binder was loaded into the mould of the manual press machine and the mould cover put back in place. Finally, the block was pressed and ejected. In step four, after production, the blocks were stored under cover and covered with polythene for 24 hours. After 24 hours, they were watered and covered once more with polythene for 6 days before the polythene was removed. After this curing period, the blocks were ready for testing. 
Table 1 Mix proportion of compressed stabilised laterite blocks

\begin{tabular}{|c|c|c|c|c|c|}
\hline \multirow[t]{3}{*}{ Soil type } & \multicolumn{5}{|c|}{ Production of blocks by fixing $2 \% \mathrm{C}$ and varying $\mathrm{GA}$ from 0 to $10 \%$} \\
\hline & Binder & & & & Code \\
\hline & Cement & GA & Salla & Water & Code \\
\hline \multirow{6}{*}{ Laterite } & \multirow{6}{*}{$2 \%$} & $0 \%$ & Fixed & OMC & $2 \%+0 \% \mathrm{GA}$ \\
\hline & & $2 \%$ & Fixed & OMC & $2 \% \mathrm{C}+2 \% \mathrm{GA}$ \\
\hline & & $4 \%$ & Fixed & OMC & $2 \% \mathrm{C}+2 \% \mathrm{GA}$ \\
\hline & & $6 \%$ & Fixed & $\mathrm{OMC}$ & $2 \% \mathrm{C}+6 \% \mathrm{GA}$ \\
\hline & & $8 \%$ & Fixed & OMC & $2 \% \mathrm{C}+8 \% \mathrm{GA}$ \\
\hline & & $10 \%$ & Fixed & OMC & $2 \% \mathrm{C}+10 \% \mathrm{GA}$ \\
\hline
\end{tabular}

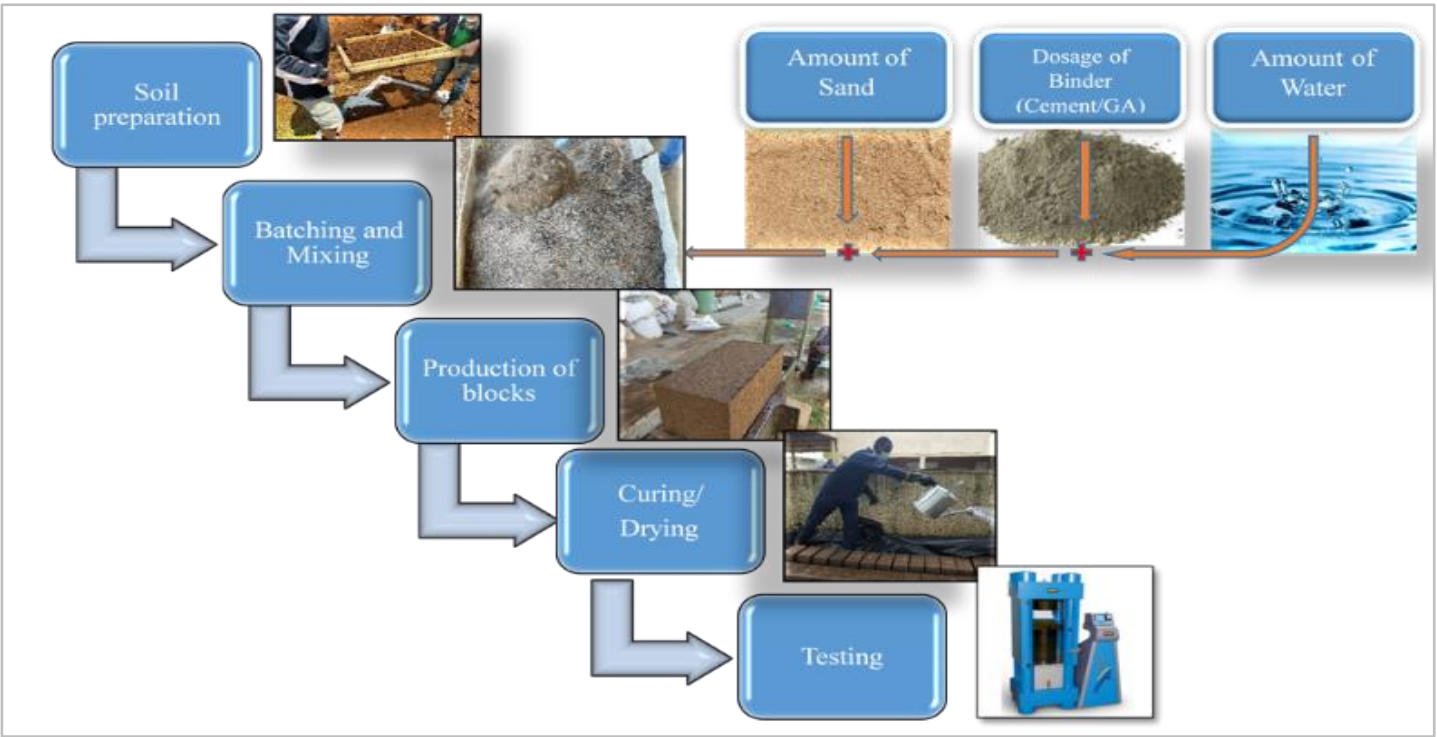

Figure 2 Block production process

\subsubsection{Water absorption test of blocks}

Water-absorption test was used to determine the moisture content of a material as a percentage of its dry weight. The test was done in accordance with the specifications in the code [39]. The blocks were weighed, dried in an oven at $105^{\circ} \mathrm{C} \pm 5{ }^{\circ} \mathrm{C}$, and then reweighed under standard conditions. Thereafter, the blocks were immersed in cold water for 24 hours.

The procedure of water-absorption test was as follows. The dry weight of the specimen was measured. Then, the specimen was immerged in water for 24 hours. The new weight of the specimen was measured. The percentage of water absorption was calculated based on Equation (1), where, $W_{a}$ is the mass of the block after absorption, $W_{b}$ is the mass of the block before absorption, $W_{\text {absorption }}$ is the percentage water absorption on dry basis (\%). Figure 3 shows the condition of the blocks after 24 hours of total immersion in water (Equation 1).

$W_{\text {absorption }}=\frac{\left(W_{a}-W_{b}\right)}{W_{b}} \times 100$

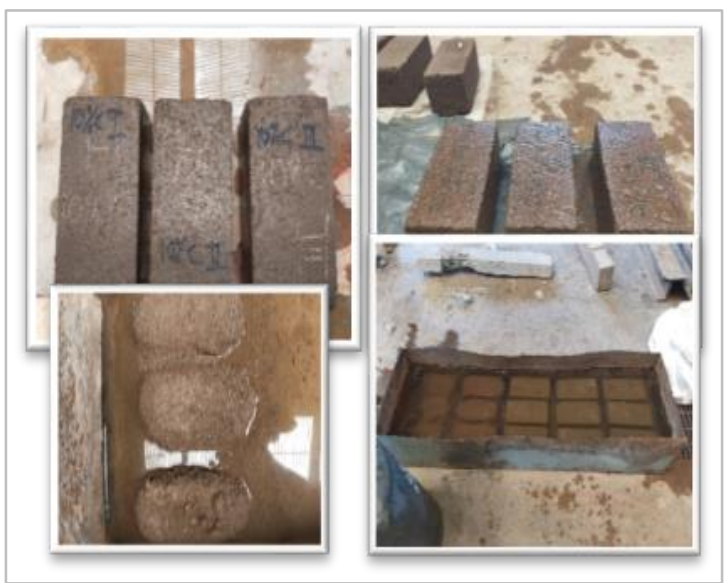

Figure 3 Conducting the water absorption test

3.2.4Calculation of the dry density of block

The dry density of the blocks was determined at 7, 14 and 28 days. The test was conducted in accordance with the Nigerian Industrial Standard [40]. The sample was weighed, dried in an oven, and then reweighed under standard conditions. The dry density of blocks was calculated based on Equation 2, where, $W_{d}$ is the 
weight of the dried block $(\mathrm{kg}), V$ is the volume of the block $\left(\mathrm{m}^{3}\right)$, and $\gamma_{d}$ is the dry density $\left(\mathrm{kg} / \mathrm{m}^{3}\right)$.

$\gamma_{d}=\frac{W_{d}}{V}$

\subsubsection{Compressive strength test}

The compressive strengths of the blocks at 7,14 and 28 days were determined in compliance with the specifications in the standard [41]. The blocks were weighed and their dimensions measured. The necessary information such as the width and length of the blocks, the rate at which the load was applied to the block was entered into the Universal Testing Machine (UTM). The blocks were then placed between the trays of the Universal Testing Machine (UTM) so that the centre of the block coincided with the loading axis of the machine. After this, the load was applied at a rate of $0.05 \mathrm{~N} / \mathrm{mm}^{2} / \mathrm{s}$ until the block failed, after which the maximum load and the maximum compressive strength of the blocks were recorded. The formula for calculating the compressive strength $\left(C_{s}\right.$ in $\left.\mathrm{MPa}\right)$ is given by Equation 3 , where $P$ is the maximum compressive load of the blocks $(\mathrm{N})$ and $A\left(\mathrm{~mm}^{2}\right)$ is the area of the blocks. Figure 4 shows the blocks prepared for the test (a), the arrangement of the block between the two trays of the UMT (b), the failure of the block under compression (c) and the state of the block after failure (d).

$c_{S}=\frac{P}{A}$

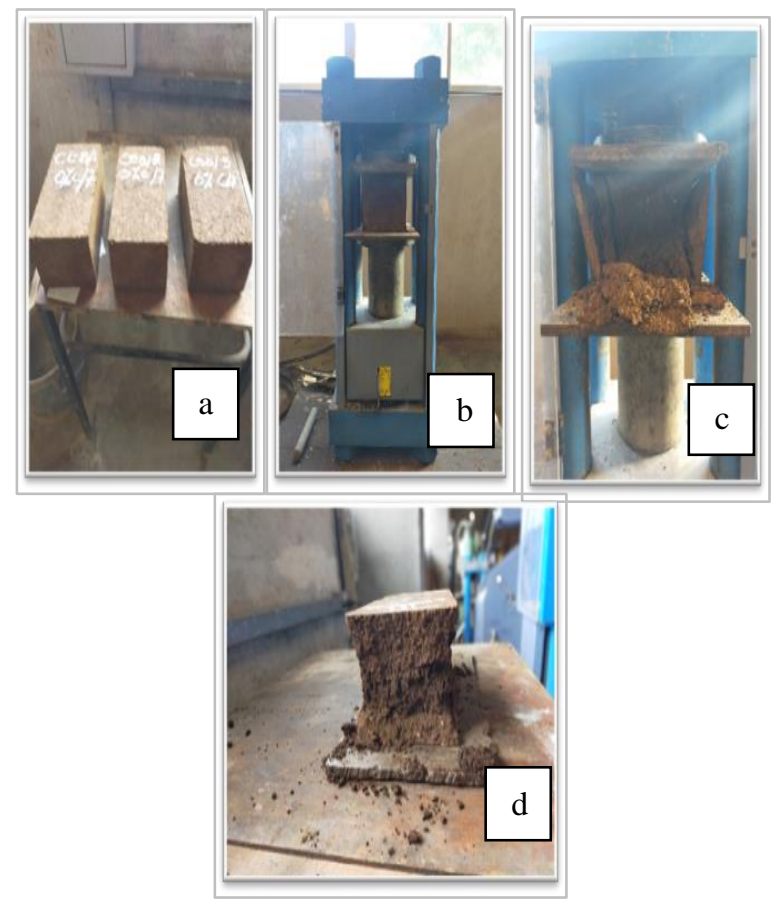

Figure 4 Testing in compression of blocks

\section{Results and discussion}

4.1Effect of GA on the physical properties of compressed laterite blocks stabilised with $2 \%$ of cement and various percentages of GA

4.1.1Water absorption of compressed stabilized laterite blocks

The results of the water absorption test blocks stabilized with $2 \%$ of cement and various percentages of GA are presented in Table 2.

The water absorption test is one of the most important criteria in evaluating the performance of blocks. The strength and durability of the blocks depend on the absorption rate of the blocks [42]. Water absorption is a factor used to assess the durability of earthen blocks in a wet environment and is an indicator of the resistance of blocks to immersion [43].

According to [44], water absorption is a very indispensable property in masonry. It can affect the quality of the blocks (after their production) and later also affect the bond strength between the blocks and the mortar in a masonry structure. For this reason, the materials constituting a block should have the lowest possible water absorption capacity.

As shown in the table, the blocks with $2 \% \mathrm{C}+0 \% \mathrm{GA}$, $2 \% \mathrm{C}+2 \% \mathrm{GA}, 2 \% \mathrm{C}+4 \% \mathrm{GA}$ and $2 \% \mathrm{C}+6 \% \mathrm{GA}$ did not resist total immersion in water for 24 hours for the different ages (7, 14 and 28 days). Only the blocks with $2 \% \mathrm{C}+8 \% \mathrm{GA}$ and $2 \% \mathrm{C}+10 \% \mathrm{GA}$ did not crumble after immersion in water for 24 hours. In addition, all water absorption values obtained are below the maximum limit value (15\%) set by the Kenyan standard [39]. The highest water absorption value is $6.4 \%$ (for $2 \% \mathrm{C}+10 \% \mathrm{GA}$ at 14 days). This is approximately 2.3 times lower than the maximum limit value set by the Kenyan standard [39]. In contrast, for the water absorption results previously obtained for blocks stabilized only with cement, the highest water absorption value is $16.8 \%$. This is 2.6 times higher than the highest water absorption value for blocks with $2 \% \mathrm{C}$ and $\mathrm{GA}(6.4 \%$ for $2 \% \mathrm{C}+10 \% \mathrm{GA})$.

This reduction in the percentage of water absorption obtained for blocks with GA is explained by the emulsifying property of GA which allows it to fill the voids in the cement microstructure, increase the density of the material and create bonds between different particles thus reducing the voids between the different particles [7, 20, 34, 45]. 
In addition, [32] confirmed that GA is a stabilizer and waterproofing agent used in mud coatings. For this reason, GA is traditionally used in mud plasters as a binder to prevent houses from the effects of heavy rains [46]. Indeed, the stabilization of biopolymerbased soils is done by the formation of "hydrogel" which strengthens the bonds of the particles and ensures the waterproofing of the material thus obtained [7. 20] [47-49]. That is, the emulsifying property of GA leads it to fill voids and create bonds between different particles [20,34]. As the durability of blocks is related to their water absorption rate $[6$, 24], it can be predicted from these findings that blocks with good water absorption performance $(2 \% \mathrm{C}+8 \% \mathrm{GA}$ and $2 \% \mathrm{C}+10 \% \mathrm{GA})$ could be used for construction. This means GA has a positive impact on the durability performance of earthen blocks against water deterioration. Previous research using guar and xanthan gums as stabilisers in earthen blocks has also found that these gums have a positive impact on the performance of blocks against water [21]. Furthermore, based on previous research, it can also be predicted that unlike cement, GA would not compromise the hygroscopic properties of earthen blocks [21].

Table 2 Water absorption of compressed stabilized laterite blocks

\begin{tabular}{|c|c|c|c|c|}
\hline $\begin{array}{l}\text { Age } \\
\text { (days) }\end{array}$ & $\begin{array}{l}\text { Percentage of } \\
\text { binders }\end{array}$ & $\begin{array}{l}\text { Water absorption } \\
(\%)\end{array}$ & Observation & \\
\hline \multirow{6}{*}{7} & $2 \% \mathrm{C}+0 \% \mathrm{GA}$ & Not measurable & Blocks crumbled before $24 \mathrm{~h}$ & NA \\
\hline & $2 \% \mathrm{C}+2 \% \mathrm{GA}$ & Not measurable & Blocks crumbled before $24 \mathrm{~h}$ & NA \\
\hline & $2 \% \mathrm{C}+4 \% \mathrm{GA}$ & Not measurable & Blocks crumbled before $24 \mathrm{~h}$ & NA \\
\hline & $2 \% \mathrm{C}+6 \% \mathrm{GA}$ & 4.5 & The shape of the blocks becomes irregular & \\
\hline & $2 \% \mathrm{C}+8 \% \mathrm{GA}$ & 4.5 & Good condition & \\
\hline & $2 \% \mathrm{C}+10 \% \mathrm{GA}$ & 4.9 & Good condition & \\
\hline \multirow{6}{*}{14} & $2 \% \mathrm{C}+0 \% \mathrm{GA}$ & Not measurable & Blocks crumbled before $24 \mathrm{~h}$ & NA \\
\hline & $2 \% \mathrm{C}+2 \% \mathrm{GA}$ & Not measurable & Blocks crumbled before $24 \mathrm{~h}$ & NA \\
\hline & $2 \% \mathrm{C}+4 \% \mathrm{GA}$ & Not measurable & Blocks crumbled before $24 \mathrm{~h}$ & \\
\hline & $2 \% \mathrm{C}+6 \% \mathrm{GA}$ & Not measurable & Blocks crumbled before $24 \mathrm{~h}$ & \\
\hline & $2 \% \mathrm{C}+8 \% \mathrm{GA}$ & 4.8 & Good condition & \\
\hline & $2 \% \mathrm{C}+10 \% \mathrm{GA}$ & 6.4 & Good condition & \\
\hline \multirow{6}{*}{28} & $2 \% \mathrm{C}+0 \% \mathrm{GA}$ & Not measurable & Blocks crumbled before $24 \mathrm{~h}$ & NA \\
\hline & $2 \% \mathrm{C}+2 \% \mathrm{GA}$ & Not measurable & Blocks crumbled before $24 \mathrm{~h}$ & NA \\
\hline & $2 \% \mathrm{C}+4 \% \mathrm{GA}$ & Not measurable & Blocks crumbled before $24 \mathrm{~h}$ & NA \\
\hline & $2 \% \mathrm{C}+6 \% \mathrm{GA}$ & Not measurable & Blocks crumbled before $24 \mathrm{~h}$ & NA \\
\hline & $2 \% \mathrm{C}+8 \% \mathrm{GA}$ & 3.8 & Good condition & \\
\hline & $2 \% \mathrm{C}+10 \% \mathrm{GA}$ & 6.1 & Good condition & \\
\hline
\end{tabular}


4.1.2Dry density of compressed stabilized laterite blocks with $2 \%$ of cement and various percentages of GA

The results of the dry density of blocks stabilized with $2 \%$ of cement and various percentages of GA are shown in Figure 5. The dry density of the blocks is closely related to the compressive strength of the blocks and inversely to the water absorption [42, 43].

The dry density results of the blocks stabilized with $2 \%$ cement and various percentages of GA show that these blocks have a dry density that varies from 1684.4 $\mathrm{kg} / \mathrm{m}^{3}$ to $1978.2 \mathrm{~kg} / \mathrm{m}^{3}$. All the dry density values are within the range of the recommended dry density, i.e. $1500 \mathrm{~kg} / \mathrm{m}^{3}$ to $2000 \mathrm{~kg} / \mathrm{m}^{3}$ [12]. It is important to note that the dry densities of the blocks with $2 \% \mathrm{C}+8 \% \mathrm{GA}$ are always the highest for the different ages. This means that this composition $(2 \% \mathrm{C}+8 \% \mathrm{GA})$ represents the optimum for obtaining blocks with the highest dry density. Controlling the dry density of blocks is very important, as the compressive strength is related to the density of the blocks [12]. It is probably because of this high density that these types of blocks showed the lowest percentage of water absorption at 28 days $(3.8 \%)$ and the highest compres sive strength at 28 days (4.23 MPa). This is because the reaction between cement and GA forms calcium silicate hydrate (C-S$\mathrm{H})$ that is denser and in greater quantity than the C-S$\mathrm{H}$ obtained from cement alone, which further improves the material properties and leads to better performance[34, 45]. Dry density results of laterite soil stabilised with GA without cement showed that dry density decreases with increasing GA content [22, 50]. This result was also observed in the case of soil stabilisation with other types of gums [20, 49]. In comparison to these results, it is clear that when the cement content is kept constant and the GA content is increased, the dry density of the blocks also increases. This is due to the fact that the combination of cement with GA produces huge amounts of $\mathrm{CSH}$, which is the cause of the increase in density of the materials [34, 45]. From these findings, it can be concluded that when mixed with cement GA has a positive impact on the dry density of blocks.

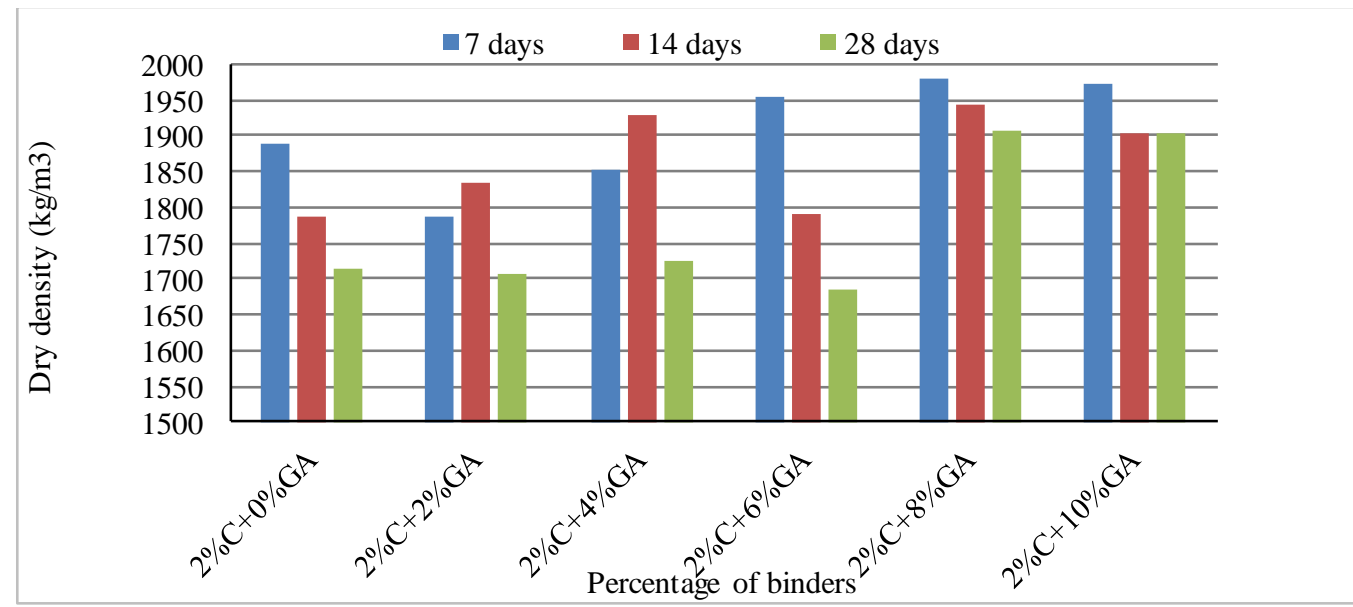

Figure 5 Dry density of compressed stabilized laterite blocks with $2 \%$ of cement and various percentages of GA

4.2Effect of GA on the compressive strength of compressed laterite blocks stabilised with $2 \%$ of cement and various percentages of GA

The results of the compressive strength of blocks stabilised with $2 \%$ cement and varying the GA content from 0 to $10 \%$, with a step of 2 , are presented in Figure 6.

As shown in Figure 6, it can be seen that all blocks stabilized with $2 \%$ cement and different percentages of GA (from 0 to $10 \%$ ) show a cumulative gain in compressive strength with age. By adding $2 \%$ and $10 \%$ GA to the blocks with $2 \%$ cement, the 28 -day compressive strength of the control blocks drops by $39.31 \%$ and $25.75 \%$, respectively. This gives compressive strengths below the minimum value of 2.5 MPa recommended by the Kenyan standard [39] (2.010 MPa for 2\% GA and $2.459 \mathrm{MPa}$ for $10 \% \mathrm{GA}$ ). On the other hand, based on the standard [51] which recommends a minimum compressive strength of $2.068 \mathrm{MPa}$ for blocks, the compressive strength of blocks with $2 \%$ cement and $10 \%$ GA is satisfactory. Moreover, it is observed that by adding 4, 6 and $8 \%$ GA to the blocks with $2 \%$ cement, the compressive strength at 28 days increases by $17.09 \%, 23.22 \%$ and $27.81 \%$, respectively compared to the control blocks with $2 \%$ cement. The compressive strength of the blocks with $2 \%$ cement and 4, 6 and $8 \%$ GA at 28 days 
are therefore higher than the minimum compressive strength value set by the Kenyan standard [39].

The fact that the compressive strength of the blocks decreases for $2 \%$ and $10 \%$ GA can be explained by the fact that the combination of these percentages with $2 \%$ cement is not adequate to obtain a good cohesion between the different materials and allow the blocks to have a high compressive strength [47]. Thus, the amount of $2 \%$ added GA is found to be insufficient to allow a good reaction between the different mixed materials. On the other hand, the amount of $10 \%$ GA added turns out to be too large to have an adequate reaction and good adhesion of the materials. This is confirmed by previous research which shows that there is always an optimal amount of gums that gives good performance in soil stabilisation and the higher contents of gum make the soil reinforcement effect decreased[7, 20, 21], [47-49]. For this reason, it is clear from the results obtained that the range of $4 \%$ to $8 \% \mathrm{GA}$ is adequate to obtain good performance of the blocks. Moreover, the fact that GA increases the compressive strength of the blocks is explained by the fact that GA is a good natural stabilizer and has the property of increasing the cohesion of soil particles [52]. Thus, by combining it with cement, it not only strengthens the soilstructure, but also ensures perfect adhesion between the soil and the cement, as it is a natural glue. This increases the performance of the blocks. Another explanation that supports this hypothesis from a scientific point of view is the hydrogel phenomenon. Indeed, the stabilization of biopolymer-based soils are done by the formation of "hydrogel" which strengthens the bonds of the particles and ensures the waterproofing of the material thus obtained [21], [47-49]. In other words, by combining GA with cement, hydrogel is formed that became finer than the soil particles and penetrates the pores to firmly bind the particles together [7]. In addition, the study of GA as an admixture in concrete has reported that the reaction between cement and GA forms Calcium Silicate Hydrate (C-S-H) denser and in higher amounts than that of cement and improves the properties of the concrete and leads to better performance. However, in the case of soil stabilization with lime, it has been reported that it is the formation of C-S-H that is responsible for soil stabilization [53, 54]. This means that the reaction between the cement and the GA that increases this C-S-H is further responsible for improving the performance of stabilized soil blocks, as it is known to have a strong binding capacity and is responsible for the strength of the blocks [12, 54,55]. These results are in agreement with the research of [19] who found that the biopolymer, specifically Xanthan gum, improves the compressive strength of blocks. This ability of GA to contribute to the production of $\mathrm{C}-\mathrm{S}-\mathrm{H}$ in quantity in the presence of cement comes from the fact that GA contains the following three minerals: sepiolite (a hydrated magnesium silicate), palygorskite (an aluminium-magnesium silicate) and mordenite (a zeolite mineral) [26]. These three minerals are known for their binding properties, excellent chemical stability and thermal resistance, and resistance to acid attack, respectively [32, 36, 37]. These three minerals all contain silicate which, upon reaction of cement with water, therefore increasing the amount of C-S-H. From these findings, it can be concluded that GA has a positive impact on the performance of compressed stabilised laterite blocks in terms of compressive strength.

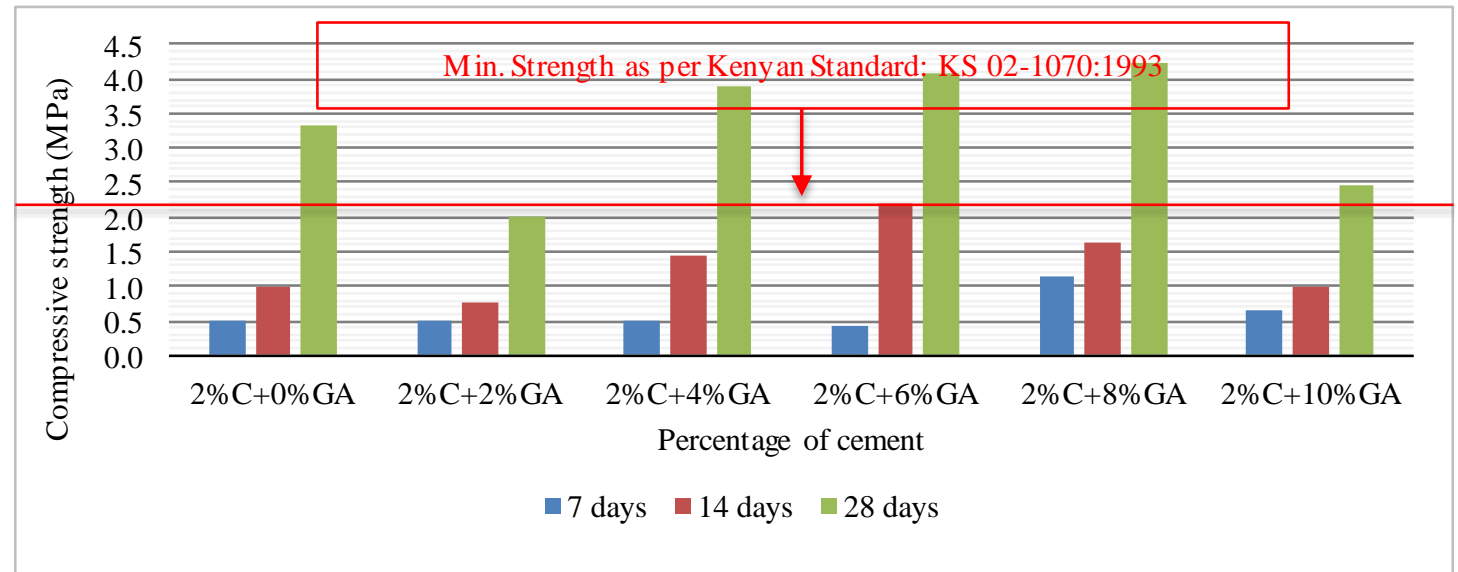

Figure 6 Compressive strength of compressed stabilised laterite blocks with $2 \%$ of cement and various percentages of GA 


\subsection{Limitations of experimental study}

This work did not carry out the effect of aging on the performance of the blocks stabilised with cement and GA. Therefore, it is recommended that studies on the laterite blocks stabilised with $2 \%$ of cement and various contents of GA should be carried out up to 90 days after curing to check the trend in the results of the various tests. This study considered analysis only up to 28 days. In addition, research should be carried out on GA-stabilised laterite blocks to determine their thermal conductivity. The scope of this study did not include thermal conductivity of the laterite blocks stabilised with GA. A complete list of abbreviations is shown in Appendix I.

\section{Conclusion}

From the above-mentioned experimental work, it has been found that blocks stabilized with $(2 \% \mathrm{C}+8 \% \mathrm{GA})$ and $(2 \% \mathrm{C}+10 \%)$ did not crumble into water after 24 hours of immersion and blocks with $(2 \% \mathrm{C}+8 \% \mathrm{GA})$ gave the best results of water absorption rate. As for the dry density of blocks, the dry density values of all blocks stabilised with GA fell within the recommended range and at 28 days, blocks with $(2 \% \mathrm{C}+8 \% \mathrm{GA})$ gave the highest value of dry density. By stabilizing the laterite blocks with $(2 \% \mathrm{C}+8 \% \mathrm{GA})$, the compressive strength of control blocks stabilized with $2 \%$ of cement was increased from $3.312 \mathrm{MPa}$ to $4.233 \mathrm{MPa}(27.80 \%)$. The combination of $(2 \% \mathrm{C}+8 \% \mathrm{GA})$ was observed as the optimum for getting best performance of blocks stabilized with GA. Therefore, it can be concluded that blocks with ( $2 \% \mathrm{C}+8 \% \mathrm{GA})$ could be considered for possible use in construction. This work can be extended to the determine the creep behaviour of blocks stabilised with cement and GA.

\section{Acknowledgment}

The authors would like to express their gratitude to the African Union Commission (AUC) and Japan International Cooperation Agency (JICA) for their support of this research.

\section{Conflicts of interest}

The authors have no conflicts of interest to declare.

\section{References}

[1] Kasinikota P, Tripura DD. Evaluation of compressed stabilized earth block properties using crushed brick waste. Construction and Building Materials. 2021.

[2] Reddy BV, Mani M, Walker P. Earthen dwellings and structures: current status in their adoption. Springer; 2019.

[3] Miccoli L, Müller U, Fontana P. Mechanical behaviour of earthen materials: a comparison between earth block masonry, rammed earth and cob. Construction and Building Materials. 2014; 61:327-39.

[4] Danso H, Martinson B, Ali M, Mant C. Performance characteristics of enhanced soil blocks: a quantitative review. Building Research \& Information. 2015; 43(2):253-62.

[5] Sharma V, Marwaha BM, Vinayak HK. Enhancing durability of adobe by natural reinforcement for propagating sustainable mud housing. International Journal of Sustainable Built Environment. 2016; 5(1):141-55.

[6] Medvey B, Dobszay G. Durability of stabilized earthen constructions: a review. Geotechnical and Geological Engineering. 2020; 38(3):2403-25.

[7] Jang J. A review of the application of biopolymers on geotechnical engineering and the strengthening mechanisms between typical biopolymers and soils. Advances in Materials Science and Engineering. 2020.

[8] Patel AJ, Patel VM, Patel MA. Review on partial replacement of cement in concrete. In UKIERI concrete congress-concrete research driving profit and sustainability 2015 (pp. 831-7).

[9] Chang I, Lee M, Tran AT, Lee S, Kwon YM, Im J, et al. Review on biopoly mer-based soil treatment (BPST) technology in geotechnical engineering practices. Transportation Geotechnics. 2020.

[10] Losini AE, Grillet AC, Bellotto M, Woloszyn M, Dotelli G. Natural additives and biopolymers for raw earth construction stabilization-a review. Construction and Building Materials. 2021.

[11] Dabou B, Kanali C, Abiero-gariy Z. Structural performance of laterite soil stabilised with cement and blue gum (Eucaly ptus Globulus) wood ash for use as a road base material. International Journal of Engineering Trends and Technology. 2021; 69(9):257-64.

[12] Riza FV, Rahman IA, Zaidi AM. A brief review of compressed stabilized earth brick (CSEB). In international conference on science and social research 2010 (pp. 999-1004). IEEE.

[13] Peng C. Calculation of a building's life cycle carbon emissions based on ecotect and building information modeling. Journal of Cleaner Production. 2016; 112:453-65.

[14] Hoff EC. Appraisal of the sustainability of compressed stabilized earthen masonry. Dissertations and Student Research, University of Nebraska - Lincoln.2016.

[15] Jeong MS, Noh DH, Hong E, Lee KS, Kwon TH. Systematic modeling approach to selective plugging using in situ bacterial biopolymer production and its potential for microbial-enhanced oil recovery. Geomicrobiology Journal. 2019; 36(5):468-81.

[16] Lee S, Im J, Cho GC, Chang I. Laboratory triaxial test behavior of xanthan gum biopolymer-treated sands. Geomechanics and Engineering .2019; 17(5):445-52.

[17] Tran AT, Chang I, Cho GC. Soil water retention and vegetation survivability improvement using microbial biopolymers in drylands. Geomechanics and Engineering. 2019; 17(5):475-83.

[18] Huang J, Kogbara RB, Hariharan N, Masad EA, Little DN. A state-of-the-art review of polymers used in soil 
stabilization. Construction and Building Materials. 2021.

[19] Benzerara M, Guihéneuf S, Belouettar R, Perrot A. Combined and synergic effect of algerian natural fibres and biopoly mers on the reinforcement of extruded raw earth. Construction and Building Materials. 2021.

[20] Joga JR, Varaprasad BJ. Effect of xanthan gum biopolymer on dispersive properties of soils. World Journal of Engineering. 2020; 17(4):563-71.

[21] Muguda S, Lucas G, Hughes PN, Augarde CE, Perlot $\mathrm{C}$, Bruno AW, et al. Durability and hygroscopic behaviour of biopolymer stabilised earthen construction materials. Construction and Building Materials. 2020.

[22] Saleh MS, Bala AB. The use of gum Arabic as a lateretic soil stabilizer. Journal of Sciences and Multidisciplinary Research, Cenresin Publications. 2010.

[23] Rigassi V. Compressed earth blocks: manual of production. CRAterre-EAG, GATE. 1985.

[24] Randall RC, Phillips GO, Williams PA. The role of the proteinaceous component on the emulsify ing properties of gum Arabic. Food Hydrocolloids. 1988; 2(2):13140.

[25] Verbeken D, Dierckx S, Dewettinck K. Exudate gums: occurrence, production, and applications. Applied Microbiology and Biotechnology. 2003; 63(1):10-21.

[26] Elinwa AU, Abdulbasir G, Abdulkadir G. Gum Arabic as an admixture for cement concrete production. Construction and Building Materials. 2018; 176:20112.

[27] Satti SA, Ahmed YH. Use of gum Arabic (Acacia Seyal) as concrete admixture. In conference proceedings civil engineering 2018 (pp.198-202).

[28] Athman CM, Abuodha SO, Nyomboi T. Use of gum Arabic as a superplasticizer in selfcompacting concrete. International Journal of Innovative Science and Modern Engineering. 2018; 5(4):8-13.

[29] Mbugua R, Salim R, Ndambuki J. Effect of gum Arabic karroo as a water-reducing admixture in cement mortar. Case Studies in Construction Materials. 2016; 5:10011.

[30] Bozabe RK, Toukourou CA, Gbaguidi GA, Hounkonnou MN. Study of the physico-mechanical characteristics of micro-concrete tiles produced locally from gum Arabic. Africa Science: International Journal of Science and Technology. 2013; 9 (1): 1-5.

[31] Ndububa EE. Performance characteristics of gum Arabic bonded particleboard made from sawdust and wood shavings. IFE Journal of Technology. 2013; 22(1):5-8.

[32] Vissac A, Bourgès A, Gandreau D, Anger R, Fontaine L. Clays \& biopoly mers - natural stabilizers for earthen construction. 2017.

[33] Montenegro MA, Boiero ML, Valle L, Borsarelli CD. Gum Arabic: more than an edible emulsifier. Products and Applications of Biopoly mers. 2012; 51:953-78.

[34] Mohamed AM, Osman MH, Smaoui H, Mohd AMA. Permeability and tensile strength of concrete with
Arabic gum biopolymer. Advances in Civil Engineering. 2017.

[35] Elinwa AU, Umar M. X-ray diffraction and microstructure studies of gum Arabic-cement concrete. Construction and Building Materials. 2017; 156:632-8.

[36] Wang DY. Novel fire retardant polymers and composite materials. Woodhead Publishing; 2016.

[37] Xavier KC, Santos MD, Santos MR, Oliveira ME, Carvalho MW, Osajima JA, et al. Effects of acid treatment on the clay paly gorskite: XRD, surface area, morphological and chemical composition. Materials Research. 2014; 17:3-8.

[38] Uzoegbo H. Dry-stack and compressed stabilised earthblock construction: exploring new frontiers in construction. Knowledge Exchange for Young Scientists (KEYS). 2016.

[39] https://webstore.kebs.org/index.php ?route=product/pr oduct\&product id=675. Accessed 25 September 2021.

[40] http://ir.jkuat.ac.ke/handle/123456789/4856. Accessed 25 September 2021.

[41] https://global.ihs.com/doc_detail.cfm?document_name $=\mathrm{BS} \% 20 \mathrm{EN} \% 20772 \% 2 \mathrm{D} 1 \&$ item_s_key $=00349060$. Accessed 25 September 2021.

[42] Muhwezi L, Achanit SE. Effect of sand on the properties of compressed soil-cement stabilized blocks. Colloid and Surface Science. 2019; 4(1):1-6.

[43] Salih MM, Osofero AI, Imbabi MS. Critical review of recent development in fiber reinforced adobe bricks for sustainable construction. Frontiers of Structural and Civil Engineering. 2020; 14:839-54.

[44] Bakar BA, Saari S, Surip NA. Water absorption characteristic of interlocking compressed earth brick units. In AIP conference proceedings 2017. AIP Publishing LLC.

[45] Mohamed AM, Osman MH, Smaoui H, Mohd AMA. Durability and microstructure properties of concrete with Arabic gum biopolymer admixture. Advances in Civil Engineering. 2018.

[46] Eltahir ME, Elsayed ME, Hamad MA. Assessment of local knowledge and traditional uses of Acacia senegal in rural areas of North Kordofan, Sudan. Agricultural Development within the Rural-Urban Continuum, University of Hohenheim, Stuttgart-Hohenheim. 2013.

[47] Muguda S, Booth SJ, Hughes PN, Augarde CE, Perlot $\mathrm{C}$, Bruno AW, et al. Mechanical properties of biopolymer-stabilised soil-based construction materials. Géotechnique Letters. 2017; 7(4):309-14.

[48] Chang I, Im J, Prasidhi AK, Cho GC. Effects of xanthan gum biopolymer on soil strengthening. Construction and Building Materials. 2015; 74:65-72.

[49] Ayeldeen M, Negm A, El-sawwaf M, Kitazume M. Enhancing mechanical behaviors of collapsible soil using two biopoly mers. Journal of Rock Mechanics and Geotechnical Engineering. 2017; 9(2):329-39.

[50] Rimbarngaye A, Mwero JN, Ronoh EK. Effect of gum Arabic content on maximum dry density and optimum moisture content of laterite soil. Available at SSRN 3920303. 
[51] ASTM E 2392. Standard guide for design of earthen wall building systems. New York, USA: American Society for Testing and Materials. 2010.

[52] Salim W, Mbugua R, Ndambuki J. Influence of gum Arabica karoo in concrete and cement mortar as retarding and water admixture. In conference: 1st symposium knowledge exchange for young scientist (KEYS) 2015.

[53] Riza FV, Rahman IA, Zaidi AM. Possibility of lime as a stabilizer in compressed earth brick. In proceedings of the international conference on advanced science, engineering and information technology 2011.

[54] Soltani A, Deng A, Taheri A, Mirzababaei M, Jaksa MB. A dimensional description of the unconfined compressive strength of artificially cemented finegrained soils. Journal of Adhesion Science and Technology. 2020; 34(15):1679-703.

[55] Mazumdar B, Hafiza R, Uddin MM. Experimental study on cement stabilized earth block (CSEB). Accelerating the World's Research. 2015.

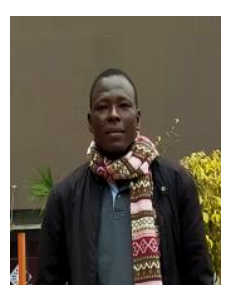

Alladjo Rimbarngaye holds a Professional Master Degree (2017) and a Bachelor Degree (2014) in Civil Engineering, both from the Ecole Nationale Supérieure des Travaux Publics (ENSTP), N'Djamena/Chad. He is currently pursuing $\mathrm{MSc}$ in Civil Engineering (Structures option) at the Pan African University, Institute for Basic Sciences, Technology and Innovation (PAUSTI), hosted at Jomo Keny atta University of Agriculture and Technology, Keny a. Email: rimbarngaye.alladjo@students.jkuat.ac.ke

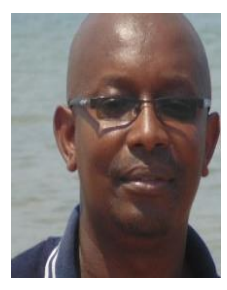

John N. Mwero is Senior Lecturer at the Department of Civil and Construction Engineering, University of Nairobi. He holds a PhD in Structural Engineering (2013) from the University of Nairobi. He holds also an MSc in Structural Engineering (2006) and a BSc in Civil Engineering (2002), both from the University of Nairobi.

Email: johnmwero1@gmail.com

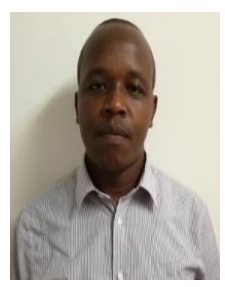

Erick K. Ronoh holds a $\mathrm{PhD}$ in Horticultural Sciences - Biosystems Engineering (2016), Gottfried Wilhelm Leibniz Universität Hannover, Germany. He also holds an MSc in Agricultural Processing Engineering (2010) and a BSc in Agricultural Engineering (2006), both from Jomo Kenyatta University of Agriculture and Technology (JKUAT), Kenya.

Email: ronoh@jkuat.ac.ke

\begin{tabular}{lll}
\multicolumn{2}{l}{ Appendix $\mathbf{1}$} \\
\hline S. No. & Abbre viation & Description \\
\hline 1 & C & Cement \\
\hline 2 & CEM IV & Pozzolanic Cement \\
\hline 3 & $\mathrm{CO}_{2}$ & Carbon Dioxide \\
\hline 4 & CSEB & $\begin{array}{l}\text { Compressed Stabilised Earth } \\
\text { Block }\end{array}$ \\
\hline 5 & C-S-H & Calcium Silicate Hydrate \\
\hline 6 & GA & Gum Arabic \\
\hline 7 & JKUAT & $\begin{array}{l}\text { Jomo Kenyatta University of } \\
\text { Agriculture and Technology }\end{array}$ \\
\hline 8 & Kg & Kilogram \\
\hline 9 & MDD & Maximum Dry Density \\
\hline 10 & OMC & Optimum Moisture Content \\
\hline 11 & SA & Setting Accelerator \\
\hline 12 & UTM & Universal Testing Machine \\
\hline 13 & WR & Water Reducer \\
\hline
\end{tabular}

